\title{
A Business Intelligence System for Risk Management in the Real Estate Industry
}

\author{
Raul Valverde \\ John Molson School of \\ Business \\ Concordia University \\ 1455 de Maisonneuve Blvd \\ Montreal, Qc, Canada
}

\begin{abstract}
The purpose of this work is to build a Business Intelligence System (BIS) for the real estate industry. The BIS be useful for risk managers interested in real estate investment. The paper identifies the main risk management related decisions that real estate professionals made on a daily basis. Risk management decision models are selected from an extensive literature review. These models are incorporated into an information system. A set of reports that will support risk management real estate decisions are designed and implemented in a prototype built to demonstrate the potential of this technology in the real estate industry. The database of the information system is populated with a sample of data collected from the real estate market of the state of California USA and results were generated to illustrate how reports can be used to support real estate risk management decisions.
\end{abstract}

\section{Keywords}

Financial Information Systems, Data mining, Real Estate, Business Intelligence, Finance, Portfolio Management, Risk Management.

\section{INTRODUCTION}

A Business Intelligence System (BIS) can be described as an interactive, computer-based system designed to help decisionmakers to solve poorly structured problems. Using a combination of models, analytical techniques, and information retrieval, such systems help develop and evaluate appropriate alternatives.

BIS should focus on strategic decisions, not operational ones. More specifically, they should contribute to reduce the risk faced by managers when they need to make decisions regarding future options. It is in this light that we have chosen to develop a BIS to assist real estate administrators in financial risk management decisions.

In the last two decades the risk management finance theory has been applied to the real estate decision making process but with not much effort of the business or academia to develop a risk management BIS that integrates this knowledge, and transmits the theory to real-world practice.

Property managers face every day critical risk management decisions as determining the price for sell or rent of a property, choice of financing, investment analysis, real estate portfolio management, real estate valuation. In these cases a BIS can be very valuable in order to minimize the risk of potential losses due to wrong decisions.

The objective of this research project is to design and develop a risk management BIS using existing decision models to assist managers in real estate decisions. Following, the decision process will be analyzed and the models to support the decisions will be identified. Finally, with the use of information technology the BIS will be designed and implemented in order to satisfy the needs of the real estate industry.

\section{LITERATURE REVIEW}

In the real estate industry are two distinct but interrelated markets: the market for tenant space and the market for investment capital. The decision making in each market is different since the space market is more concerned with the use decision whereas the investment decision is made in the capital market. In this research, the focus would be the investment capital market.

In the capital market, decisions are made based on investment analysis, in which the primary objective is the maximization of the capital return given a certain risk, or given a return, to minimize the risk. In order to achieve this objective, investors use decision support models.

The decision support models for capital market have emphasis on modern portfolio theory. Portfolio Theory assumes that unsystematic risk is reduced by including real estate in a portfolio, and perhaps by diversifying across economic areas and property types. The model assumes that are no constraints on the amount of any given asset class.

In practice these models are hard to use because real estate in particular lacks price data on frequent transactions that are comparable to price data for publicly traded stocks and bonds.

Investors traditionally have thought of equity real estate as an inefficient market in which the key to success is in the skill with which an individual investment is selected and negotiated. The general approach seems to be buying properties when they become available if they look like "good deals", with little regard for the equally important issue of how acquisition fits with other holdings in the portfolio and what effect, if any, it will have on the overall risk and return objectives of the portfolio. Investors need to assess how the real estate segment fits into their entire portfolio. This means setting risk and return objectives for the equity real estate portfolio as a whole that are compatible with the goals for the investor's entire portfolio. Devising a strategy for achieving these objectives and evaluating the extent to which individual transactions conform to the strategy and are likely to further portfolio objectives

Real estate diversification is the key in real estate investment. In diversification the combination of property type and economic regions affect the risk and return characteristics of a portfolio. Spreading assets geographically has great affect in risk if the diversification is done across economic independent regions. 
In the Capital Market the most important decision that needs to be supported is how much to put into different categories of assets and the overall risk level of the portfolio.

In order to support this decision, real estate portfolio decision models need to be implemented. These models should achieve higher-than average levels of return, and the investor must construct a portfolio involving greater-than-average risk. It also should be possible and useful to measure the risk and return and to develop, in an approximate manner, a portfolio strategy that balances the trade-off between these two performance criteria

The total risk on any investment can be decomposed into systematic and unsystematic component. Portfolio decision models focuses on the unsystematic risk that will largely disappear as an influence on the return of a well-diversified portfolio. The risk from changes in economic conditions throughout the country is systematic and will influence any portfolio, no matter how large and well diversified, because it influences each of the parts.

The capital market may have a lack of active management of real estate assets, along with changes in the environment surrounding corporate owned real estate that may result in significant value that is undetected by managers and investors alike. The potential hidden value in real estate is a function of: changes in capital market conditions, changes in firm prospects, in utilization of real estate, taxes, changes in accounting, and in factors affecting agency costs of the firm [1].

Changes in a firm's operating prospects are due either to changes in return prospects or changes in risk exposure having a similar prospect. The expected return on real estate may justify ownership (as opposed to leasing) of real estate in periods when the firm prospects are poor, but this relationship can reverse when firm prospects improve. The magnitude of the value increment created by changes in the use of a firm's real estate obviously depends on how much value the new use adds to the property.

The potential to increase firm value suggests that firms should consistently review the performance and the value of their real estate. A corporation must understand how its real estate holdings are affecting its total market value, in order to determine how to utilize this asset. This requires a valuation model of real estate within the corporate setting.

Also, there is a need of deciding which financing alternative is the most appropriate. On deciding which alternative is best we should have in mind the objectives for corporate real estate management suggested by Miles et al. [1] which are:

\section{- Cash Generation}

- Takeover prevention

- More effective utilization of the tax laws

- Minimizing agency cost

- The use of real estate financing as a market signal

- Playing the local real estate market by using the corporate advantage generated by the corporation's longtime horizon.

- Maintaining flexibility given the firm's current and expected space needs, flexibility is an important consideration while pursuing the objectives above
Since the most common choice of financing is the mortgage [2], it is important to analyze the most important components in the mortgage choice. A basic component of mortgage choice is the loan-to-value decision, the choice of mortgage instrument and the decision to prepay or default. Prepayment may be caused by a household's decision to move, by refinancing to obtain a lower rate, or to obtain more money.

Follain [2] argues that any model of mortgage choice should be consistent with several stylized facts about mortgage choice. In the case of Loan-to-Value Decision (LTV) the following facts must be taken in to consideration.

- $\quad$ LTV for the population as a whole is quite low, around $30 \%$; indeed, over one third have no mortgage at all.

- $\quad$ LTV among recent home buyers are much higher

- LTVs decline rapidly with length of stay in the house

- $\quad$ LTVs among the elderly are specially low

- Lending rules limit mortgage payment to income ratios

Follain [2] finds that the only relevant variables in the LTV models are length of stay, age and income. He finds that there is a positive relationship between income and LTV whereas the LTV decreases as age and length of stay increase. Concerning the facts that affect the Mortgage Instrument Choice [2] he proposes that any model that supports this decision must take in to account that:

- The fixed-rate-mortgage works well during noninflationary times and it remains extremely popular.

- The surge in adjusted-rate-mortgage was demand driven, being strongly related to movements in the level of interest rates

- Demand in ARM's increases modestly with income and length of stay. Short timers prefer the use of ARMs

- The demand for other instruments beside ARM's and FRM's is low

In Refinancing and Default payment decision models the following facts must be considered:

- Refinancing does not take place as rapidly as pure option pricing models would suggest.

- Default seems to depend upon LTV

- Foreclosure is relatively uncommon

An important aspect of risk management is diversification. Diversification is akin to not putting all your eggs in one basket. Lots of academic research shows that a diversified portfolio reduces risk for a given rate of return

Williams [3] was the first to suggested that the greater the relative balance of return from operating and reversion, the more diversified the portfolio, and thus the better the portfolio performance. Later Kwame Addae-Dapaah [4] found that the association between the cash flow concentration level and the portfolio performance index, and between the diversification index and the portfolio performance index was stronger than depicted by Williams[3].

Norman, Sirmans and Benjamin [4] suggested that real estate is important for portfolio diversification, although there is no consensus on the optimal amount; studies looking at longer time period hold more percentage of portfolio in real estate. There were further studies about the role of the real estate in a 
portfolio investment together with other investment such as bonds and stocks. The studies also investigated how economical factors affect the allocation between different type assets [6].

There are many studies investigating questions like "how we are going to diversify?"; "what are the dimensions of diversification?". This opens topic of cluster analysis, which partitions observed cases into relatively homogenous groups to produce an operation [7]. Abraham, Goetzmann and Watcher [8] have been using this in real estate market. The object of such analysis is to sort observations into groups, called clusters, so that the degree of similarity is high among members of the same group and low among members of different groups. This involves two considerations: (1) which variables to use in the classification; and (2) how to calculate similarity between the observations.

For variables (dimensions) to use in the classification, the most popular ones are geographic and property diversification. For property type categories, they differ among research, institutional investment and government sources, and these descriptions are generally references office, warehouse, manufacturing, retail hotel and multifamily property types [8]. While property type should not be the only diversification strategy used, this study finds that property type allocations may enhance investor returns over real estate market and/or economic cycles [9].

For geographic clustering, The studies was carried across many countries such USA [10,11,12], UK [13], and China [14]. Many findings support the notion that homogenous geographic grouping for optimized diversification must recognize the relative importance of the underlying economic factors for different property markets. Although there are clear signs of geographic influence, the clusters are not at all synonymous with "pure" geographic regions of contiguous states [15].

Veiser evaluated "Within Real Estate" diversification strategies [16] by adding controls to the experimental design to determine why one strategy is superior to another. The best strategy used sixteen dimensions (four property types in four geographic regions). In our study, our decision station are using similar strategic dimension.

After discussing "dimensions of diversification" and "how to cluster", another important theme is "optimal diversification model". Traditionally everything is based on Markowitz Portfolio Theory (MPT) [17].

Markowitz considered each investment's return as being represented by a probability distribution of expected returns over a period of time. The riskiness of each asset is based on the variability of these expected returns. Although the portfolio's mean return is a weighted average of the individual asset's mean return, the portfolio's riskiness cannot be calculated the same way due to the correlations between each asset's returns[18].

Multiple and less than perfectly correlated assets, allow minimization of unsystematic risk and choice of exposure to systematic risk for any given level of return. Portfolio diversification reduces unsystematic real estate investment risk [19]. Efficient market theories suggest that investors are not rewarded for bearing unsystematic risk and therefore should seek to minimize its presence.

There are different issues on MPT. Gold [19] believes that asset allocation in intervals rather than point estimates in traditional MPT make it easier to manage a real estate portfolio. This accounts for the fuzziness of the real estate efficient frontier. Because of this fuzziness, it would be possible that an efficient portfolio developed by meanvariance analysis may not be any more efficient than a naively diversified portfolio. Cheng and Liang [20] investigated that in practical terms, efficient portfolios may not be superior to naively diversified portfolios in a statistical sense using an efficiency test developed by Gibbons, Ross, and Shanken [21]. Tradition MPT doesn't take into account of the time variant behavior of variables of the real estate market, this leads to development of situated decision supporting system in our study. Another problem MPT includes fraction of asset but real estate asset is not divisible. We need to modify MPT to accept discrete input behavior, this leads to development of the Findlay model [22].

\section{METHODS AND REALIZATION}

The objective of our system is to support risk management decisions in the real estate industry. The primary users of the system are investors; they will use the system to support their investment decisions as the kind of property to invest in order to maximize their return. They will use the system to monitor the performance of the corporate building and to support how to finance the property and the amount of prepayment.

The proposed system will address the decisions below:

- $\quad$ How much to put into different categories of assets
-
-
-
-
-

The mathematical models to be used in our DDS are:

Findaly model [22]: To estimate the assets to include in the investment portfolio, this model was selected due to the fact that assumes that the assets included are indivisible, which is the case in real life.

Findlay [22] has proposed a portfolio model for the real estate that works fine for portfolio sizes limited to ten assets, because most unsystematic risk reduction occurs over the first ten assets.

The objective is to minimize the overall portfolio risk.

$$
Z(e)=\min \frac{\sum_{i=1}^{M} \sum_{j=1}^{M}\left(X_{i} C_{i} \sigma_{i} \rho_{i j} \sigma_{j} C_{j} X_{J}\right)}{\sum_{j=1}^{M} C_{j} X_{J}}
$$

Where

$\mathrm{Z}(\mathrm{e})=$ The objective function that calculates the variance of a portfolio of indivisible assets.

$\mathrm{Xi}=$ Either 0 or 1 , representing the decision to either invest or not invest in the asset,

$\mathrm{Ci}=$ The cost of the ith asset,

$\mathrm{Cj}=$ The cost of the jth asset, 

$\sigma i=$ The standard deviation of the ith asset
$\sigma \mathrm{j} \quad=$ The standard deviation of the $\mathrm{jth}$ asset
$\rho$ ij $=$ The correlation coefficient between assets I and $\mathrm{j}$, and
$\mathrm{CjXj}=$ The total portfolio outlay
$\mathrm{M}=\quad$ Number of assets

The Tucker model [23] is used to decide which financing choice to use. The model was selected for its powerful capability of predicting which method (fixed rate or adjustable rate) has the better probability of better performance.

The model suggests than in an efficient market, borrowers will select the least expensive mortgage. Since the mortgage most common choices are the adjustable-rate (ARM) and fixed-rate mortgage (FRM), it concentrates in these two choices.

Tucker [23] based his model on the hypothesis that the probability of borrowers selecting ARMs over FRMs increases as the interest-rate margin between the two types of mortgages increases, and decreases with increases in one-year constant maturity Treasury bill rates, and increases with FRM rate increases. Logit analysis was used to determine if financial variables are significant in determining borrower selection between fixed-rate and adjustable-rate mortgage. The probability of a borrower selecting is specified as equation 2:

$$
\begin{aligned}
& P i=\frac{1}{\left(1+\operatorname{Exp}^{(-Z i)}\right.} \\
& \mathrm{Zi}=-2.2224-18.3247 \mathrm{~T}-\mathrm{BILL}+ \\
& 101.8549 \mathrm{INTDIFF}+39.19 \mathrm{CPI}
\end{aligned}
$$

Where:

$$
\begin{aligned}
\mathrm{Pi}= & \text { Probability of selecting ARM over FRM, } \\
\mathrm{T}-\text { bill }= & \text { One-year constant maturity-Treasury bill } \\
& \text { rate }
\end{aligned}
$$

$\mathrm{CPI}=$ Percent change in consumer price index from one year prior,

$\mathrm{INTDIFF}=(\mathrm{FRM}$ interest rate $)-($ ARM interest rate $)$.

The Miles et al. performance model [1]: To model the performance of a corporate property in terms of cost of capital, the model was selected given its capability of determining if the property is not being underutilized. Miles et al. [1] suggests that firms should consistently review the performance and the value of their real estate. A corporation must understand how to utilize this asset, and this requires a valuation model of real estate within the corporate setting.

The model assumes that the cash flow after taxes coming from the firm is constant and that the firm has an infinite number of years. Equation 3 shows the value of the firm including the real estate property.

Where:

$$
\begin{aligned}
& \mathrm{VR}=\sum_{i=0}^{i=n-1} \frac{D a(i-T)}{\left(1+K w^{i}\right)}+\frac{(D a+R S)}{\left(1+K w^{n}\right)}+\sum_{i=n+1}^{i=\alpha}\left(\frac{D b}{\left(1+K w^{i}\right)}\right. \\
& \mathrm{Da}=\mathrm{S}-(\mathrm{VC} * \mathrm{US}+\mathrm{FC})
\end{aligned}
$$

$$
\begin{aligned}
& \mathrm{Vc}= \text { Value of the firm at today; } \\
& \mathrm{Da}= \text { Cash flow of the company before taxes } \\
& \text { including real estate; } \\
& \mathrm{T} \quad \text { = Taxation rate; } \\
& \mathrm{Kw}=\text { Cost of capital; } \\
& \mathrm{n} \quad=\text { Number of years that real estate; } \\
& \mathrm{RS}=\text { Real estate estimated sell value after } \mathrm{n} \text { years; } \\
& \mathrm{Db}=\text { Cash flow of the company without real estate; } \\
& \mathrm{S}=\text { Gross income before taxes of the firm; } \\
& \mathrm{VC}=\text { Variable cost; } \\
& \mathrm{US}=\text { Units sold; } \\
& \text { FC = Fixed cost. }
\end{aligned}
$$

The Hartzall model [24]: To value a property in terms of investment. The model was selected given the availability of the required data in the public information system.

Hartzell [24] begins with the premise that the rate of increase in real estate income is a function of the inflation rate modified by lease structure, real supply and demand conditions, and the degree of product enhancement or deterioration that occurs over time. In this form, real estate can be viewed as a bond whose principal is inflation-indexed and whose coupons range from zero to full indexation. Thus, the price of real estate can be reduced to the following equation.

(Current Property Value $)=($ Present Value of Net Rents Over Next T Years + Present Value of Expected Market Price in $T$ years)

$$
\begin{aligned}
& \mathrm{PO}=\sum_{\mathrm{t}=1}^{\mathrm{T}}\left(\overline{\left(\frac{\mathrm{NR}}{\left(1+\mathrm{KO}^{\mathrm{t}}\right)}\right)+}\right. \\
& E \frac{[N R 0(1+g 0+\overline{u 1})(1+g 0+\overline{u 2}) \ldots .(1+g 0+\overline{u T}) \overline{X M T}]}{\left(1+k 0^{T}\right)}
\end{aligned}
$$

Where:

P0 = Present value of future cash flows generated by the property;

$\mathrm{T}=$ Term of lease;

$$
\begin{gathered}
\mathrm{NR}=\text { Net rental income on lease (fixed over } \mathrm{T} \\
\text { years) }
\end{gathered}
$$

$\mathrm{NR} 0=$ Current level of market rents;

g0 = Current expected growth rate in property value, which reflects the expected

Economy wide inflation rate;

$\mathrm{uT}=$ Unexpected growth rate in rents in year $\mathrm{T}$ that reflects unexpected inflation, local supply 
and demand imbalances, as well as

obsolescence and enhancements, which

are interrelated with local market conditions;

MT = Price-to-rent multiple in year T;

$\mathrm{k} 0=$ Current required rate of return; and

$\mathrm{E}[. .]=$. Expected property value in $\mathrm{T}$ years

The Goldman prepayment mortgage model [25] is also included given its powerful capability of prediction of the prepayment rate for a mortgage.

The model captures four important economic effects:

1. The refinancing incentive;

2. Seasoning or age of the mortgage;

3. The amount of the year (seasonality); and

4. Premium burnout.

The Refinancing Incentive: This measures the refinancing incentive as the weighted average of recent values of $C / R$, the mortgage coupon rate divided by the mortgage-refinancing rate. For values of $\mathrm{C} / \mathrm{R}$ below one, the homeowner's prepayment option is out-of-the money, and the refinancing incentive is relatively small. Conversely, when $\mathrm{C} / \mathrm{R}$ exceeds one, the coupon is above the refinancing rate, and the incentive to refinance increases dramatically.

Seasoning: It is well known that mortgage prepayment rates rise from very low levels at issue to much higher levels as the mortgage age. The model captures the interaction between seasoning and coupon by making the seasoning effect a function of the mortgage's current $\mathrm{C} / \mathrm{R}$. Figure 1 shows the relative seasoning effects for a discount pool with $\mathrm{C} / \mathrm{R}=0.8$, a par pool with $\mathrm{C} / \mathrm{R}=1.0$ and $\mathrm{C} / \mathrm{R}=1.2$.

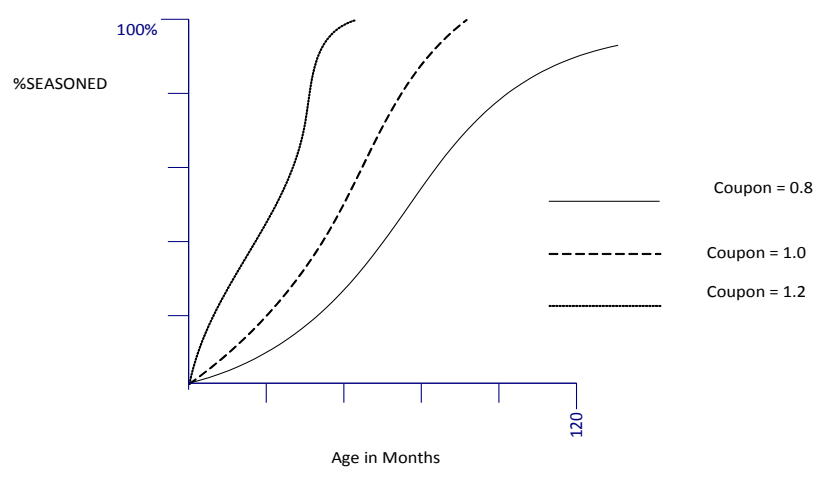

Figure 1Seasonality effect

Goldman [25] captures the effect in a series of curves, but he doesn't say how to model it mathematically. The model seems to have certain linearity and although it is difficult to determine a universal model, a linear mathematical model can approximate the effect that may be used for decision support purposes. The linear model that captures this effect is approximated using the equation 5 . This equation assumes that most of the time the term $C / R$ is more than 1 , since a $C / R$ of less than one is not attractive to analyze due to the fact that the prepayment in this case would be zero.

$$
\mathrm{S}=0.1+\frac{0.75(\mathrm{~L} / \mathrm{A})}{\mathrm{C} / \mathrm{R}}
$$

Where

$$
\begin{aligned}
& \mathrm{S}=\quad \text { Seasoning factor; } \\
& \mathrm{L}=\quad \text { Length of mortgage; } \\
& \mathrm{C} / \mathrm{R}=\text { The mortgage coupon rate divided by the } \\
& \quad \text { mortgage refinancing rate; } \\
& \mathrm{A}=\text { Age in months of the mortgage. }
\end{aligned}
$$

The basic architecture of the proposed BIS is shown in figure 2:

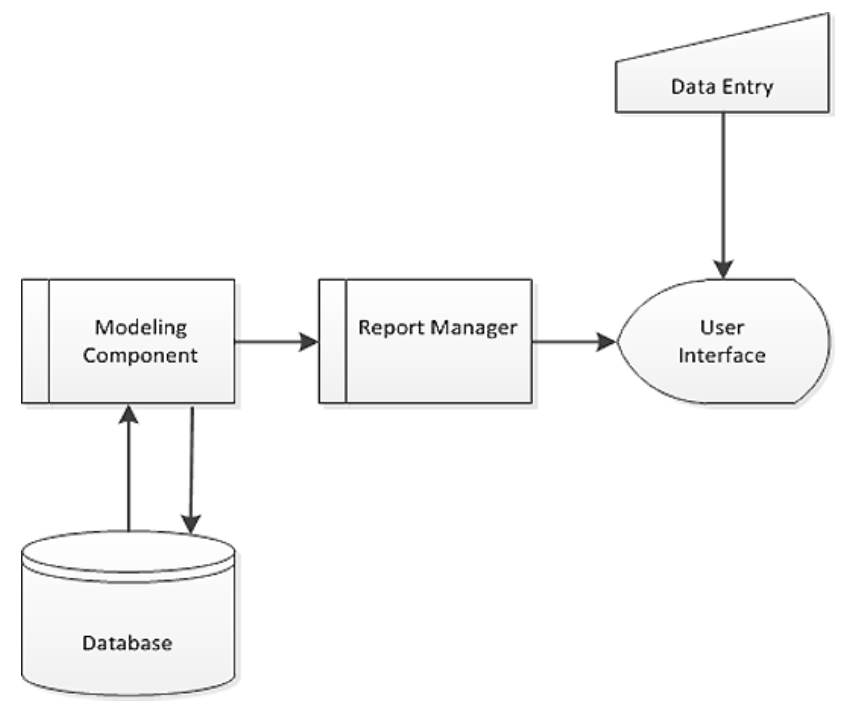

Figure 2 The BIS Architecture

The report generator is used for customized presentation of knowledge in terms of templates (comprised of forms). It can help decision-makers quickly spot patterns, trend, and proportions that exist in data

The reports that our BIS will generate are:

- Financing choice report: It will suggest the best financing choice (ARM or AFM), and the probability associated with it.

- Performance Report: It will show how the corporate building is used in terms of profitability and will suggest actions to be taken in order to improve profitability of the corporation related to the building.

- Investment report: It will suggest the assets to be bought in order to achieve a minimum risk, and the expected level of return of investment for this choice.

- Investment property valuation: It will show the investment potential value of a property.

- Amount of prepayment for a mortgage: It will suggest the percentage of prepayment for the mortgage.

Figure 3, shows the state transition diagram of our graphical user interface design. 


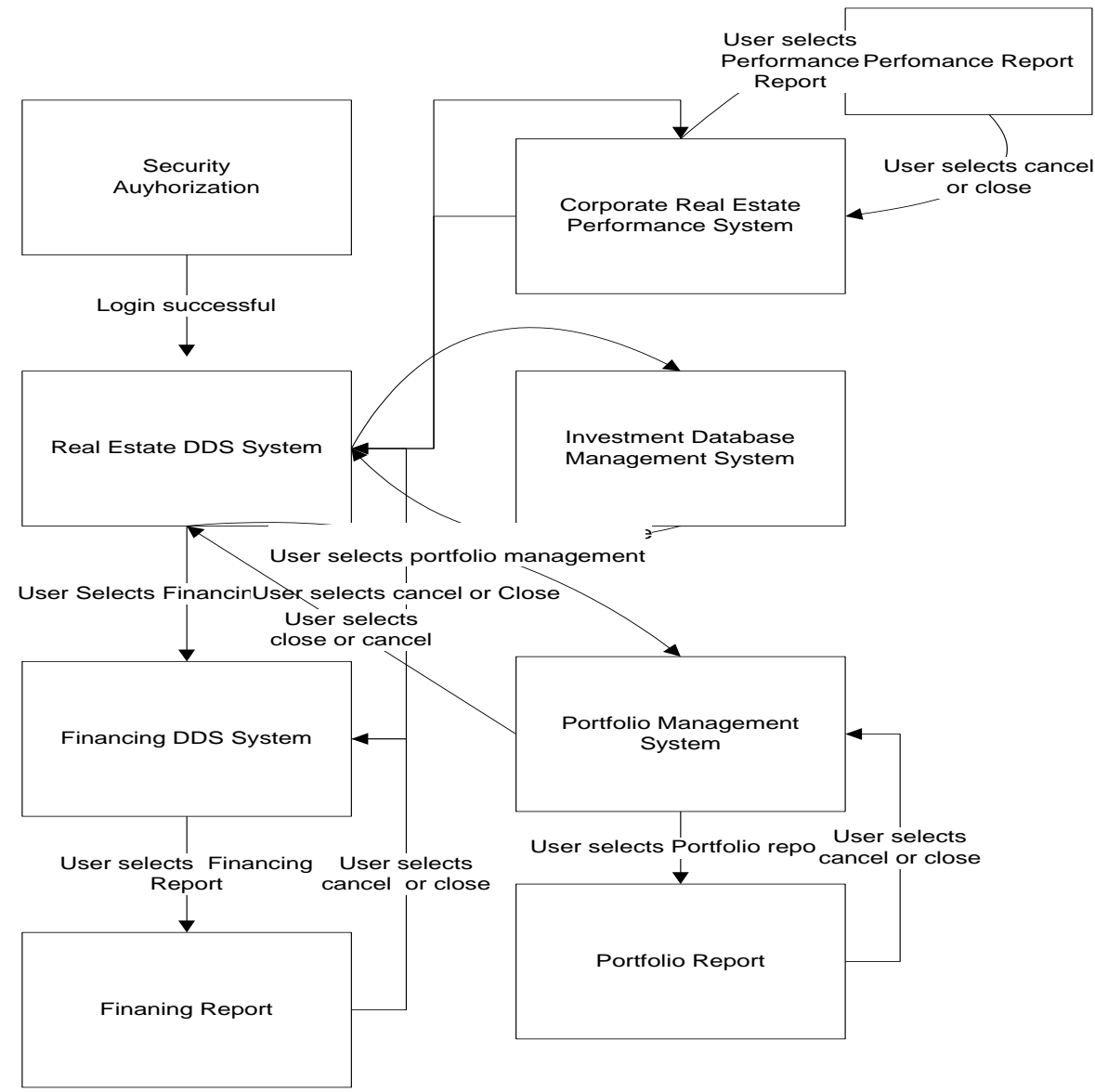

Figure 3 State transition diagram for the graphical user interface

\section{RESULTS AND DISCUSSIONS}

A prototype of the DDSS was implemented in Visual Basic .Net. The system's main menu is shown in figure 4 . The main menu is organized in four major functional areas: Investment decision support utilities, financing decision support tools and performance evaluation support tools.

The investment decision support utilities are composed of the investment database and the portfolio management system.

The investment database keeps all the data needed to calculate the real estate investment portfolio. The database (Figure 5) has three fields: Location, rate and type.

The location field keeps the geographical place of the property (NW, NE, SW, SE, Center), the rate keeps the capitalization rate on a year for the property and the type keeps the type of property (industrial, mixed-used, retail, office).

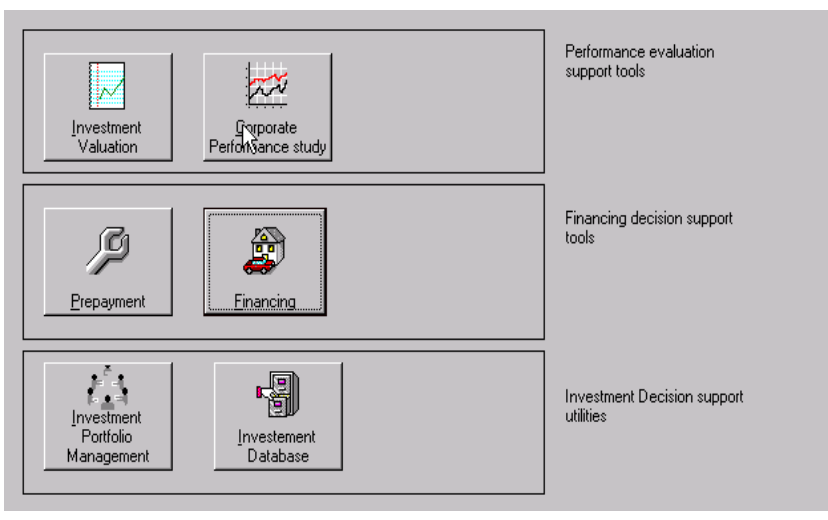

Figure 4 System's main menu

The database has the capability of updating, deleting and adding new data. In order to test the system, the database was populated with 300 records for different property types and places for the estate of California U.S for the period of 2009 2010. 


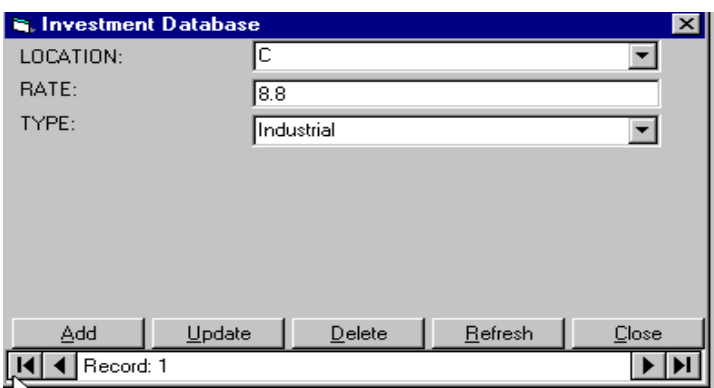

Figure 5 Investment database

The portfolio management system receives as input several investment opportunities (no maximum limit) and the user has to enter the location, type and price for each property. The system will calculate the Findlay [3] risk for all possible investment portfolios and it will report the portfolio with the lowest risk. Figure 6 shows an example with thirteen properties as input, where the suggested portfolio was composed of three assets with a Findlay risk of 0.16 out of the maximum possible risk of 12.23. A new set of 4 properties were are added and the DSS selected a new asset that gives a final result of four assets in the portfolio with a risk of 0.0043 out of the maximum risk of 12.23 , which supports the Findlay theory that the more assets you have in the portfolio the lower the investment portfolio risk.

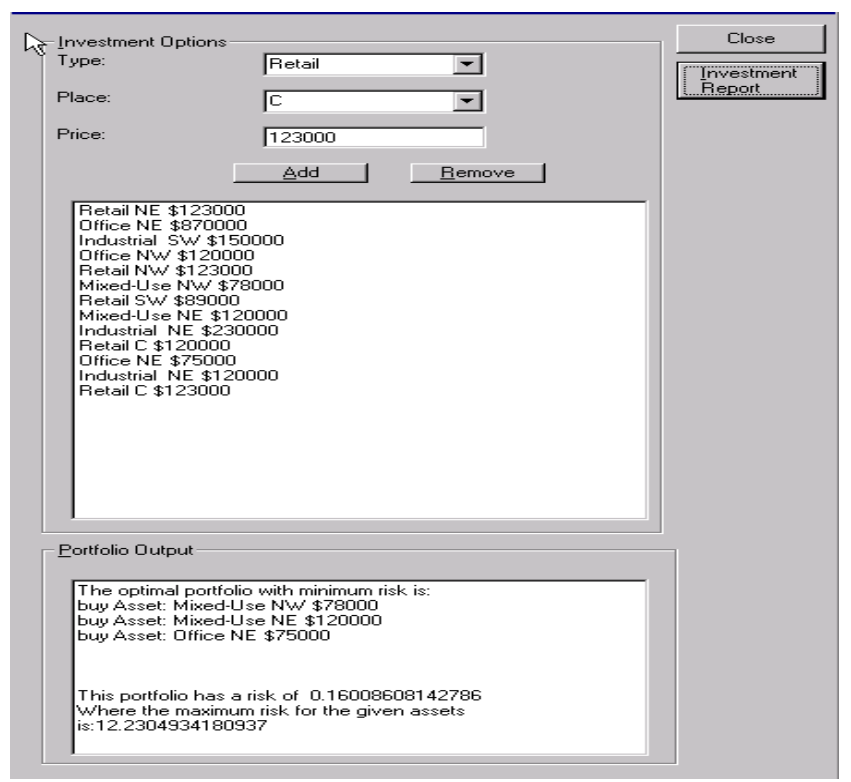

\section{Figure 6 Portfolio management system with four three assets output}

The financing decision support system is composed of the financing and prepayment systems. The prepayment system helps to decide the amount of prepayment in percentage of the mortgage when the user negotiates the mortgage at a lower rate than the original rate. The module needs the original mortgage coupon rate, the mortgage-refinancing rate, the length of the mortgage, the age of the mortgage at the time of the negotiation and the month when the payment is done. Figure 7 shows an example where the mortgage original rate is $12 \%$, the refinancing rate $11 \%$, the length of the mortgage is 240 , the age is 60 and the month of payment is March, in this case the suggested prepayment is $8.25 \%$ of the left mortgage capital.

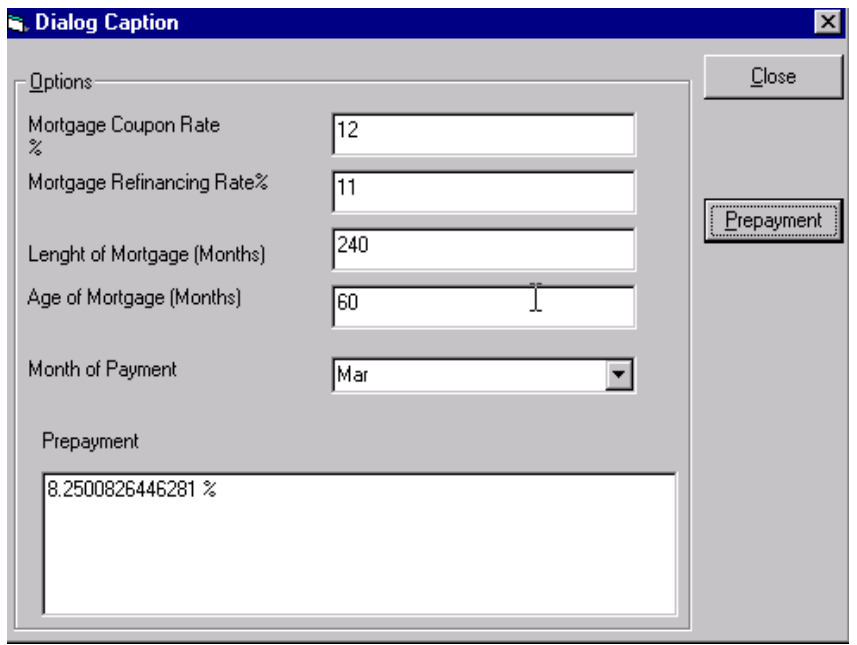

Figure 7 Prepayment module

The financing module suggests what kind of financing (ARM or FRM) shall the user chose in order to get a better rate. The module also gives the probability of the accuracy of the decision. The input variables are the region CPI, the ARM rate, the FM rate and one the year Treasury bill rate. In the example of figure 8 the CPI is $11 \%$, the ARM rate is $6 \%$, the FRM rate is $\% 8$ and the treasury bill rate is $\% 4$, for this example the module suggests the ARM mortgage with a success probability of 0.96 .

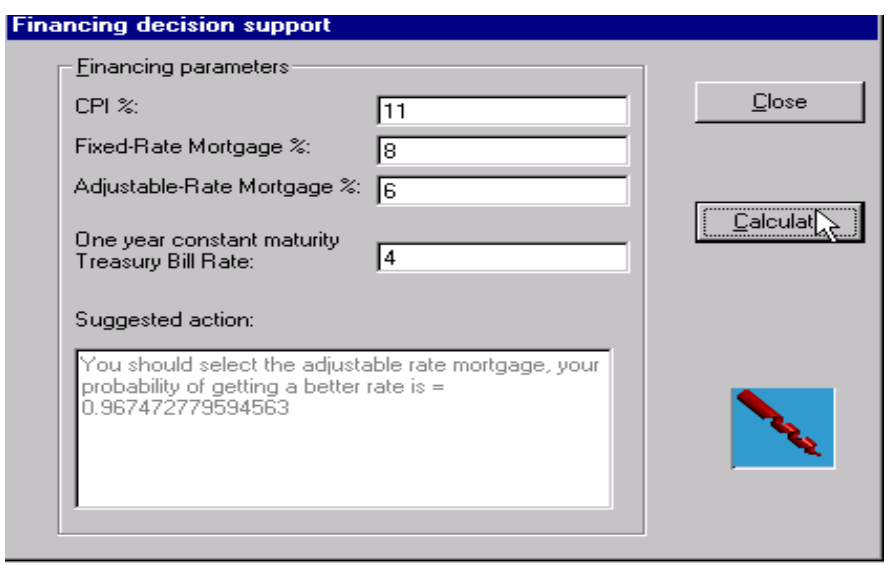

Figure 8 The financing module

The performance decision support tools are composed of the investment valuation and corporate performance study modules.

The first evaluates a property in terms of investment, given a property value, yearly rent, yearly operating costs, property number of years giving cash flow, resale value after the given number of years and the desired rate of return. The module evaluates the investment and reports the net present value of the property, which can be used for decision purposes. Figure 9 shows an example of this module, where the property value is $\$ 105,000$, yearly rent $\$ 680$, yearly expenses of $\$ 3000$, number of years of 25 , resale value of $\$ 40,000$ and desired rate of return of $\% 10$, giving a result of net present value of $\$ 122,561$. In this case the system suggests that the investor should not buy the property. 


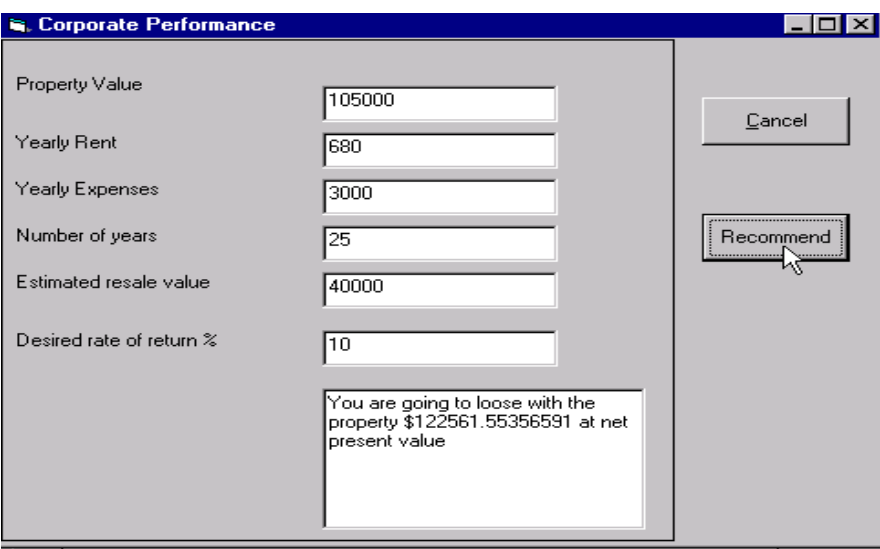

Figure 9 Investment valuation module

The corporate performance study module calculates the difference of the net present value of the firm with and without the real estate. In figure 10 the module calculates the net present value of a difference of a lawyer firm with an annual income of $\$ 1,500,0000$, annual fix cost of $\$ 300,0000$, tax rate of $\% 40$, building value of $\$ 700,0000$, building life of 25 years, resale value of $\$ 270,000$, average cost of capital of $\% 6$, estimated annual rent of $\$ 60,000$, estimated annual operating cost of $\$ 20,000$. The firm rents an office of his building to an accountant for $\$ 5,000$ a year. For this example the module calculates the difference at $-\$ 283,183$, for which it suggests to sell the property and rent a equivalent building since the sell will add net present value to the firm.

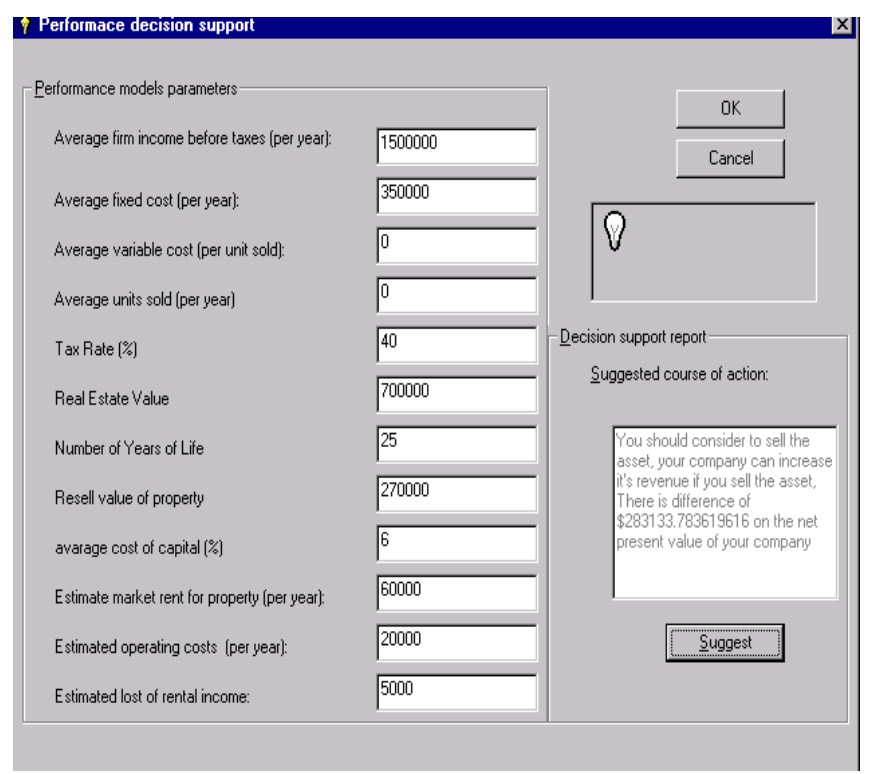

Figure 10 The corporate performance study module

\section{CONCLUSIONS}

Two different kinds of markets for the real estate industry were identified: the space and capital markets. For the capital market, the decision process was analyzed, and the requirements to support each decision were specified. In order to support the decisions, several decision models were analyzed and those that satisfied the requirements the best were selected as part of the BIS. A BIS was designed according to the specifications and it was implemented using the Visual Basic programming language and the Microsoft Access database. The system's database was populated with data from California U.S.A and the system was tested with different examples and satisfactory reports were obtained from these simulations.

During the project the most important research in real estate decision support was covered and several technologies were combined as artificial intelligence, data mining and database management systems for the purpose of supporting the decisions made in the real estate industry.

Several limitations were encountered as the availability of reliable data and the little research in the topic. On the other hand the Findlay portfolio management theory gave good results, the same for financing and performance modules although there was not enough time to measure performance given time constraints.

Finally there is a need for more research in the topic, since there is great opportunity to implement BIS in the industry given the great benefits that were presented in this research.

\section{REFERENCES}

[1] Miles, M., J. Pringle and B. Webb, "Modeling the Corporate Real Estate Decision", Journal of. Real Estate Research, 4(3), pp 47-66, 1989.

[2] Follain, J. R., "Mortgage Choice" American Real Estate and Urban Economic Associations Journal, 18(2), 125 144, 1990.

[3] Williams, J. E., Real Estate Portfolio Diversification by Sources of Return, In A.L. Schwartz Jr. and S.D. Kapplin (Eds.), Alternative Ideas in Real Estate Investment, Boston, MA: Kluwer Academic Publishers, 1995.

[4] Kwame Addae-Dapaah*, Ser Gek Wee**, M. Shahid Ebrahim***, Real Estate Portfolio Diversification by Sources of Return, Volume 8, Number 1, Journal of Real Estate Portfolio Management 2002

[5] Norman, E. J., G. S. Sirmans and J. D. Benjamin, The Historical Environment of Real Estate Returns, Journal of Real Estate Portfolio Management, 1995, 1:1, 1-24.

[6] Benjamin J.D., Sirmans G.D and Zietz, E N., Returns and Risk on Real Estate and Other Investments: More Evidence Volume 7, Number 3, the Journal of Real Estate Portfolio Management 2000.

[7] Giliberto M., Hamelink F., Hoesli M., and MacGregor B., Optimal Diversification within Mixed-Asset Portfolios using a Conditional Heteroskedasticity Approach: Evidence from the U.S. and the U.K. Journal of Real Estate Portfolio Management, 1999, 5:1, 31-25

[8] Abraham, J., Goetzmann W. and Wachter S., "Homogeneous Groupings of Metropolitan Housing Markets," Journal of Housing Economics 3(1994) 186206.

[9] Anderson Arthur \& Company, Managing the Future, Chicago: Institute of Real Estate Management, Fall 1991.

[10] Mueller, G. R., \& Laposa, S. P. (1995). Property type diversification in real estate portfolios. The Journal of Real Estate Portfolio Management, 1(1), 39-50.

[11] Cheng P. and Black R.T, Geographic Diversification and Economic Fundamentals in Apartment Markets: A Demand Perspective 1998. 4:2, 93-105.

[12] Theron R. Nelson, and Susan L. Nelson, Regional Models for Portfolio Diversification, Volume 9, Number 
1, 2003 of the Journal of Real Estate Portfolio Management.

[13] Williams J.E., Real Estate Portfolio Diversification and Performance of the Twenty Largest MSAs, Volume 2, Number 1, 1996 of the Journal of Real Estate Portfolio Managemen

[14] Weng S., Huang Y., Potential for Portfolio Diversification Across China's Real Estate Markets, AsRES 2004 Conference

[15] Ping Cheng and Roy T. Black, Geographic Diversification and Economic Fundamentals in Apartment Markets: A Demand Perspective 1998. 4:2, 93-105.

[16] Veiser T., Evaluating "Within Real Estate" Diversification Strategies, Volume: 6, Issue Number: 1, 2000 of Journal of Real Estate Portfolio Management

[17] Markowitz, Harry M. (1952). Portfolio selection, Journal of Finance, 7 (1), 77-91.

[18] Tucker W. Francis, Real Estate Investment Thesis A Real Estate Portfolio Optimizer Utilizing Spreadsheet Modeling with Markowitz Mean-Variance Optimization And Monte Carlo Simulation, Johns Hopkins University, 2000
[19] Gold R, Why the Efficient Frontier for Real Estate is "Fuzzy", 1:1, 59-66, 1995 of Journal of Real Estate Portfolio Management

[20] Ping Cheng, Youguo Liang, Optimal Diversification: Is It Really Worthwhile?, 6:1, 7-16, 2000 of Journal of Real Estate Portfolio Management

[21] Gibbons, Michael R., Stephen A. Ross, and Jay Shanken, 1989, A test of the efficiency of a given portfolio, Econometrica 57, 1121-1152

[22] Findlay, M. C., Hamilton, C. W., Messner, S. D. and Yormark, J. S., "Optimal. Real Estate Portfolios", AREUEA Journal, 7 (3), 298-317, 1979.

[23] Tucker, M. "Adjustable-Rate and Fixed-Rate Mortgage Choice: A Logit Analysis". Journal of Real Estate Research, 4(2), pp. 81-91, 1989.

[24] Hartzell, D. J., Shulman, D. G., Langetieg, T. C. and Leibowitz, M. L. "A look at real estate duration", Journal of Portfolio Management 15(1), 16-24, 1987.

[25] Richard R. and Roll R. 1989, "Modeling prepayments on fixed-rate mortgage-backed securities," Journal of Portfolio Management, 15(3), pp. 73-82. 